\title{
Surface Enhanced Raman Scattering of Crystal Violet with Low Concentrations Using Self-Assembled Silver and Gold-Silver Core-Shell Nanoparticles
}

\author{
Bahareh Morovvati and Rasoul Malekfar* \\ Atomic and Molecular Physics, Department of Physics, Tarbiat Modares University, Tehran, \\ P.O. Box 14115-175, I.R. Iran \\ *Corresponding Author Email: Malekfar@modares.ac.ir
}

Received: Mar. 11, 2018, Revised: Jun. 8, 2018, Accepted: Jul. 18, 2018, Available Online: Dec. 27,2019

DOI: $10.29252 /$ ijop.13.2.89

\begin{abstract}
The active substrates in surface enhanced Raman scattering (SERS) spectroscopy were prepared through selfassembly of nanoparticles on functionalized glasses. Colloidal silver nanoparticles (Ag NPs) were prepared chemically in two different sizes by reduction of $\mathrm{AgNO}_{3}$ using trisodium citrate and sodium borohydride. Gold-silver core-shell nanoparticles were also prepared to compare between the optical behaviors of their silver shell and Ag NPs. Absorption spectra of nanoparticles were measured by ultravioletvisible (UV-Vis.) spectroscopy, and their approximate sizes were determined by dynamic light scattering (DLS). The core-shell nanoparticles were approximately the same size as the largest Ag NPs (35 $\mathrm{nm})$ and had the same maximum absorption wavelength. The potential of these substrates for detection applications was investigated with $1 \mathrm{M}$ and $0.1 \mathrm{mM}$ solutions of Raman-active molecule of crystal violet (CV) dye. The Raman enhancement signal was recorded for $0.1 \mathrm{mM}$ solution with $532 \mathrm{~nm}$ laser wavelength, and the obtained spectra enhancement factor (EF) was calculated. EF values indicated that although the silver and gold-silver core-shell nanoparticles had the same surface plasmon resonance, the substrate with smaller Ag NPs had the highest enhancement factor compared to other substrates, which was $9.5 \times 10^{3}$, and the coreshell substrate even had a slightly lower enhancement factor in compare with the large Ag NPs.
\end{abstract}

KEYWORDS: Crystal Violet, gold-silver coreshell nanoparticles, self-assembly, silver nanoparticle, Surface-enhanced Raman Spectroscopy, SERS.

\section{INTRODUCTION}

Surface enhanced Raman scattering (SERS) spectroscopy is an analytical tool in the detection and characterization of chemical structures of molecules. There are several major factors that can contribute to the SERS enhancement effect, including: electromagnetic enhancement resulting from collective free-electron oscillation, which enhances Raman signals of molecules adsorbed on the metal surface [1], and (2) charge-transfer between the metal nanoparticles and molecule (known as the chemical enhancement) [2-3].

Therefore, noble metal nanoparticles play a key role in achieving high sensitivity in SERS enhancement. In recent years, $\mathrm{Au}$ and $\mathrm{Ag}$ nanoparticles, due to their localized surface plasmon resonance (LSPR), have attracted attentions and play significant roles in SERS investigations. Au colloids are biocompatible and stable in comparison with $\mathrm{Ag}$ nanoparticles. These advantages make gold nanoparticles a viable option for using in SERS substrates. However, Ag nanoparticles show higher enhancement factors in visible spectrum [4-6]. Therefore, deposition of Ag shell on $\mathrm{Au}$ core can lead to further enhancement of Raman signal with significant properties of Au nanoparticles [7-8]. 
There are different techniques for reducing the metal shell to the surface of core particles [7,9]. The chemical reduction with citrate is used in this study. This method enables us to create a required number of nanoparticles easily and in a controlled manner.

There exist different methods of fabrication of good reproducible, low-cost, highly uniformed and efficient SERS substrates. Self-assembly of nanoparticles on surfaces of glass slides is one of the best choices to achieve uniformed SERS substrates with the ability to be reproduced [10-11].

In this study, self-assembly method was used to fabricate SERS substrates by $\mathrm{Ag}$ and $\mathrm{Au} @ \mathrm{Ag}$ NPs. The SERS activity of substrates assembled by Au@Ag and Ag NPs were compared for low concentrations of crystal violet molecule as an analyte.

\section{Experimental Procedures}

\section{A. Materials}

Silver nitrate $\left(\mathrm{AgNO}_{3}, 99 \%\right)$, hydrogen tetrachloroaurate (ш) hydrate $\left(\mathrm{HAuCl}_{4} .3 \mathrm{H}_{2} \mathrm{O}\right.$, 99.9\%), trisodium citrate dihydrate $\left(\mathrm{C}_{6} \mathrm{H}_{5} \mathrm{Na}_{3} \mathrm{O}_{7} .2 \mathrm{H}_{2} \mathrm{O}, \quad 99 \%\right), \quad$ (3-aminopropyl) triethoxysilane (APTES, 99\%), sulfuric acid $\left(\mathrm{H}_{2} \mathrm{SO}_{4}\right)$, hydrogen peroxide $\left(\mathrm{H}_{2} \mathrm{O}_{2}\right)$, ammonia water $\left(\mathrm{NH}_{3} . \mathrm{H}_{2} \mathrm{O}\right)$ and crystal violet were purchased from Merck Millipore. The stock solution was prepared by dissolving the crystals of the dye and preparing the aqueous solutions using de-ionized water.

\section{B. Preparation of Silver Nanoparticles}

Ag-1 nanoparticles were prepared using the following method. $30 \mathrm{ml}$ of $2 \mathrm{mM} \mathrm{NaBH}_{4}$ solutions were used in a cold bath as a reducing and stabilizing agent. $10 \mathrm{ml}$ of $1 \mathrm{mM}$ $\mathrm{AgNO}_{3}$ were added to this solution while stirring over a period of 3 minutes. The solution eventually turned yellow indicating that the reaction was completed [12].

Ag-2 NPs were synthesized by the citrate reduction method and $\mathrm{AgNO}_{3}$ solution $(1 \mathrm{mM}$, $20 \mathrm{ml}$ ) as a metal salt precursor was heated. After boiling under vigorous stirring, $1.4 \mathrm{ml}$ of triodium citrate $(1 \mathrm{wt} \%)$ was injected into the solution. During the process, this solution was heated for another 10 minutes [13]. Then a green-gray colloid was removed from the heating device and stirred until cooled to reach room temperature.

\section{Preparation of gold nanoparticles}

Gold nanoparticles were synthesized according to the Frens method [14]. In order to do this, $20 \mathrm{ml}$ of $\mathrm{HAuCl}_{4}$ solution $(0.01 \mathrm{wt} \%)$ was heated to boiling. Then, $0.4 \mathrm{ml}$ of $1 \mathrm{wt} \%$ trisodium citrate aqueous solution was added to the boiling solution under vigorous stirring. When the color of mixture turned to wine-red, the heating was stopped.

\section{Preparation of gold-silver core-shell nanoparticles}

$\mathrm{Au}$ colloid was heated and then $\mathrm{AgNO}_{3}$ solution $(5 \mathrm{ml}, 20 \mathrm{mM})$ and sodium citrate (5ml, $13.5 \mathrm{mM})$ simultaneously were added drop-by-drop into gold colloids under vigorous stirring. The mixture was continuously heated and stirred for 20 minutes, resulting in the formation of $\mathrm{Au} @ \mathrm{Ag}$ core-shell nanoparticles [15].

\section{E. Preparation of Substrates}

The glass slides were cleaned with DI water and ethanol successively under ultrasonication. Then, the glass slides were immersed in piranha solution $\left(\mathrm{H}_{2} \mathrm{SO}_{4} / \mathrm{H}_{2} \mathrm{O}_{2}=7: 3 \mathrm{v} / \mathrm{v}\right)$ and boiled at $80{ }^{\circ} \mathrm{C}$ for 30 minutes. After being washed with deionized water, they were immersed in solution of $\mathrm{H}_{2} \mathrm{O}_{2} / \mathrm{NH}_{3} / \mathrm{H}_{2} \mathrm{O}(1: 1: 5$, $\mathrm{v} / \mathrm{v} / \mathrm{v})$ for 30 minutes at $75{ }^{\circ} \mathrm{C}$. Next, the activated slides were immersed into an ethanol solution of APTES (1\%) for $24 \mathrm{~h}$ to form a silane monolayer. Then, the glass slides were rinsed several times with ethanol to remove unbound silane and dried at $110{ }^{\circ} \mathrm{C}$ for 1 hour [16].

\section{F. Self-Assembly Nanoparticles on Glass Slide}

The amine-surface substrates were dipped into the prepared colloidal solutions. After 12 hours, the self-assembled nanoparticles slides were rinsed with deionized water and dried at 
room temperature. By deposition of $\mathrm{Ag}-1$, Ag-2, and Au@Ag NPs on the glass slides, three samples were prepared and named as sample-1, sample-2, and sample-3, respectively.

\section{G. Sample Preparation for SERS}

The aqueous solution of crystal violet at different concentrations were prepared. Desired low concentrations of crystal violet were dropped on the substrates. After evaporating the solvents, the SERS activities of the substrates were measured.

\section{H. Characterization}

UV-Visible absorption spectra of $\mathrm{Ag}, \mathrm{Au}$ and $\mathrm{Au} @ \mathrm{Ag}$ colloidal solutions were recorded by a PG-Instruments model $\mathrm{T} 80+$ spectrometer with a $10 \mathrm{~mm}$ quartz cell. Baselines were recorded using milli-Q pure water and before measurements, the samples were diluted twice. The fluorescence emission spectrum was recorded using a spectrofluorometer (Gilden photonics) equipped with a xenon lamp. The size distribution of $\mathrm{Ag}$, $\mathrm{Au}$ and $\mathrm{Au} @ \mathrm{Ag}$ NPs in the colloids were measured by a Zetasizer Nano-ZS system (Malvern Instruments). The measurements were performed at room temperature with a laser wavelength of 632.8 $\mathrm{nm}$. Raman and SERS spectra were collected using a Nicolet Almega Dispersive Raman Spectrometer (Thermo Fisher Scientific Inc.) equipped with a maximum power of $100 \mathrm{~mW}$, $532 \mathrm{~nm}$ laser. All spectra were collected at $10 \mathrm{~mW}$ of power, 32 accumulations.

\section{RESULTS AND DISCUSSION}

\section{A. UV-Vis Absorption and Fluorescence Emission Spectra analysis}

The optical properties of the nanoparticles were studied via UV-Visible spectroscopy. Fig. 1 shows the SPR maximum absorption, $\lambda_{\max }$, of silver, gold and gold-silver core-shell nanoparticles. The Ag-1 and Ag-2 colloids exhibit one SPR band around 392 and $428 \mathrm{~nm}$, respectively.

The absorption peak at $521 \mathrm{~nm}$ belongs to the surface plasmon absorption of gold NPs. After the addition of silver salt solution, the plasmon peak of the Au nanoparticles shifts toward the blue region $\left(\lambda_{\max }=411 \mathrm{~nm}\right)$. This blue shift reveals a change in the plasmonic properties of nanoparticles and indicates surface modification of $\mathrm{Au}$ NPs. The shape of the curve was not changed, which can be concluded that no aggregation of nanoparticles was occurred. The presence of only one peak in absorption band confirmed the formation of a uniform shell on the core particles in the colloid [17].

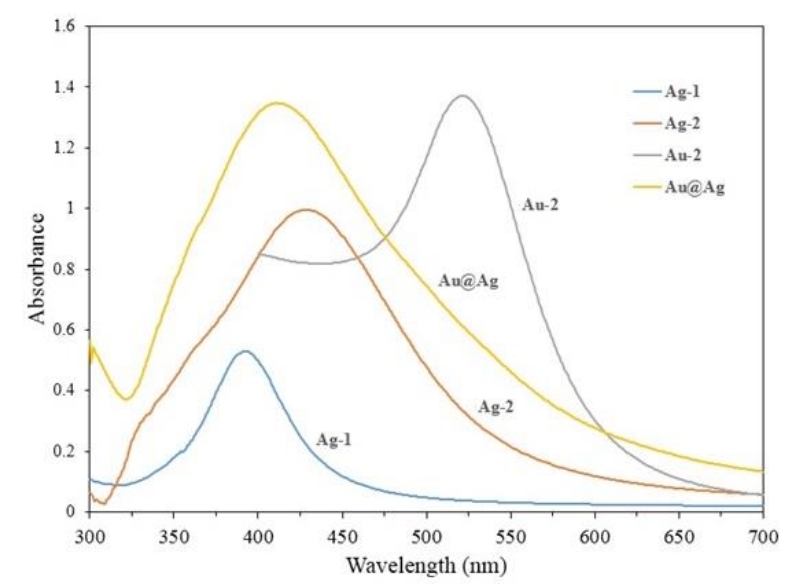

Fig. 1. UV-Vis absorption spectra of Ag-1, Ag-2, $\mathrm{Au}$ and $\mathrm{Au} @ \mathrm{Ag}$ nanoparticles.

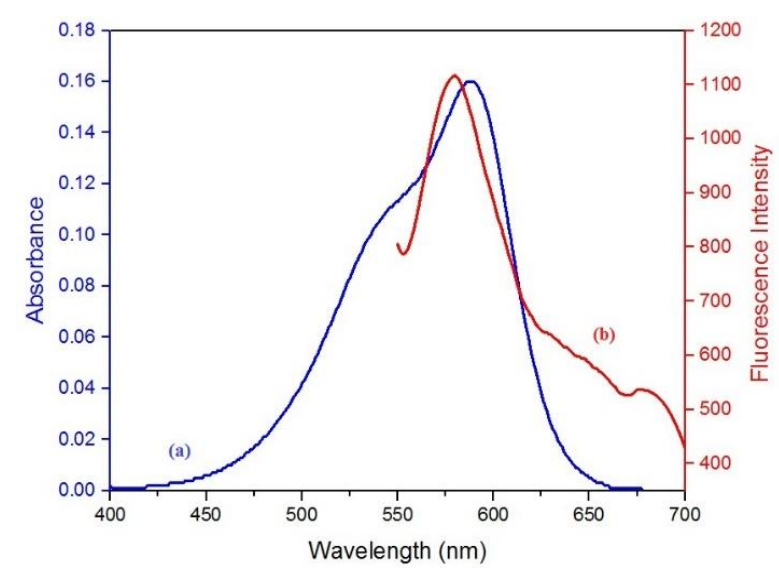

Fig. 2. (a) UV-Vis absorption and (b) fluorescence emission spectra of crystal violet.

Figure 2(a) shows the absorption spectra for crystal violet, that maximum absorbance occurred at $588 \mathrm{~nm}$. Because the maximum absorbance of $\mathrm{CV}$ molecule is near excitation laser line $(532 \mathrm{~nm})$, the resonance has occurred. However, this overlap can increase the Raman intensities and decrease the detection limits, but a significant fluorescence background is revealed. This background can 
be very stronger than the Raman signals, but using the prepared substrates, significant enhancement of SERS will be achieved (I ISERS $\propto \mathrm{E}^{4}$ while $\mathrm{I}_{\text {emission }} \propto \mathrm{E}^{2}$ ) and simultaneously the fluorescence quenching occurred [18].

The fluorescence spectrum is shown in Fig. 2(b). Crystal Violet dissolved in water and was excited at $532 \mathrm{~nm}$ wavelength with an interval of $1 \mathrm{~nm}$. The emission range was set to 550-700 $\mathrm{nm}$. The maximum emission wavelength is around $580 \mathrm{~nm}$.

\section{B. DLS Measurement}

The size of nanoparticles was characterized by Dynamic Light Scattering (DLS). The results obtained for $\mathrm{Au}, \mathrm{Ag}$ and $\mathrm{Au} @ \mathrm{Ag}$ NPs are presented in Fig. 3. Analysis of the results indicate that the hydrodynamic diameters of nanoparticles were 8, 35, 13 and $39 \mathrm{~nm}$ for the Ag-1, Ag-2, $\mathrm{Au}$ and $\mathrm{Au} @ \mathrm{Ag}$ NPs, respectively. The change in the size of the core-shell and Au NPs, confirmed the presence of a $25 \pm 0.7 \mathrm{~nm}$ thick silver shell around the gold core.

\section{Raman Spectra Analysis}

The procedure used for the SERS substrate preparation is presented in Fig. 4. The pretreatment of the glasses with the piranha solution is carried out for the purpose of improving the deposition, which in itself means that it adds more hydroxyl groups; however, it should be noted that this solution is very aggressive.

The organosilanes are directly attached to the substrate via siloxane bond and the monolayer is formed on the surface. Finally, with dip coating of the substrates in the colloids, the nanoparticles conjugated with the reactive moiety of this layer [19].

In CV molecule, there is a central carbonium ion and three benzene rings are symmetrically around the center (Fig. 5). This molecule displays a propeller-like shape. The rings are tilted at an angle of $30^{\circ}$ to the carbonium plane. The point group symmetry of $\mathrm{CV}$ is $\mathrm{D}_{3}$. Despite discussions about the symmetry of the molecule in the liquid phase and on metal substrates [20], the study showed that symmetry of CV solution is $\mathrm{D}_{3}$ [21].
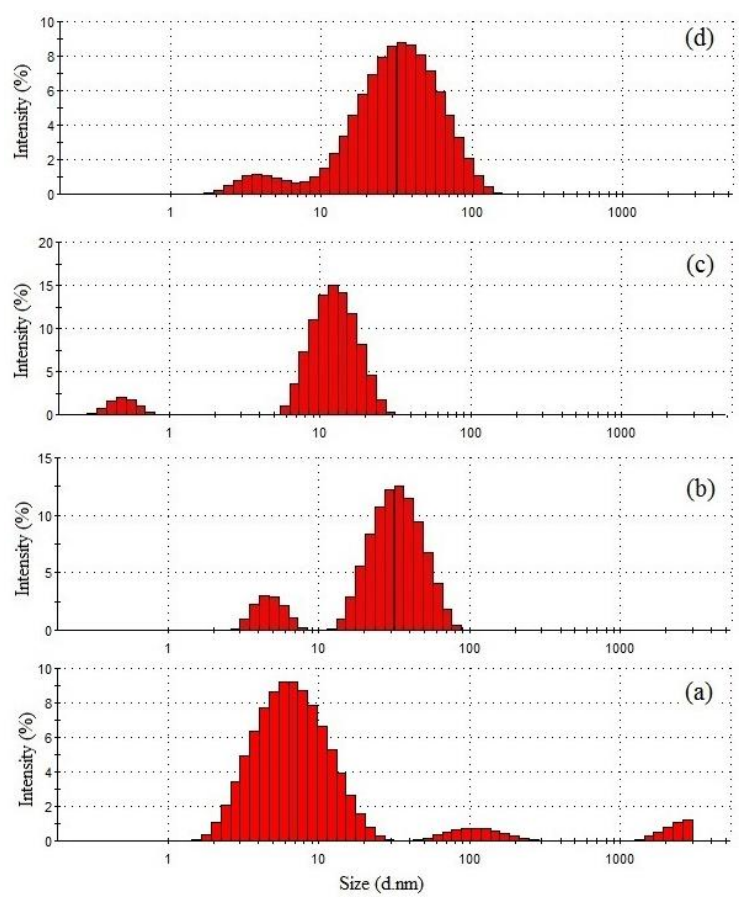

Fig. 3. Measurement of particle size distribution of (a) Ag-1, (b) Ag-2, (c) Au, and (d) $\mathrm{Au} @ \mathrm{Ag}$ nanoparticles by DLS.

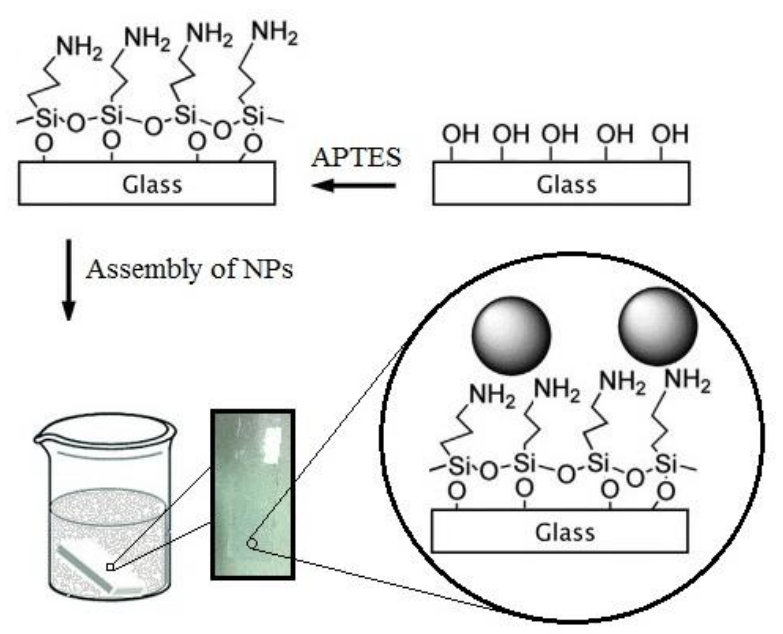

Fig. 4. The diagram represents the preparation steps of glass functionalization via APTES and deposition of nanoparticles on the modified glass by immersing the slides in a colloidal nanoparticle.

The Raman spectra of the crystal violet molecule are shown in Fig. 6. Raman spectra of $\mathrm{CV}$ powder show that the $\mathrm{CV}$ peaks are very stronger than the solutions, whereas the intensity of signals in solutions are very weak and they can hardly be seen. The peak arising from the symmetric stretching vibration of C- 
$\mathrm{C}$ appears at $1626 \mathrm{~cm}^{-1}$ in $\mathrm{CV}$ powder and $1 \mathrm{M}$ solution and $1630 \mathrm{~cm}^{-1}$ in $0.1 \mathrm{mM}$ solution, respectively. Another peak at $1549 \mathrm{~cm}^{-1}$ are assigned to the stretching vibration of $\mathrm{C}_{\text {ring }} \mathrm{N}$ and the symmetric bending of $\mathrm{CH}_{3}$. This peak does not appear in the SERS spectra. In addition, the peaks at 1391 and $1188 \mathrm{~cm}^{-1}$ in powder sample, are attributed to the $\mathrm{C}-\mathrm{H}$ bending and the antisymmetric stretching of $\mathrm{CC}_{\text {center }} \mathrm{C}$, respectively. In the solutions, the peak intensities strongly decreased, so that in $0.1 \mathrm{mM}$ concentration, most of the peaks were hardly characterized.

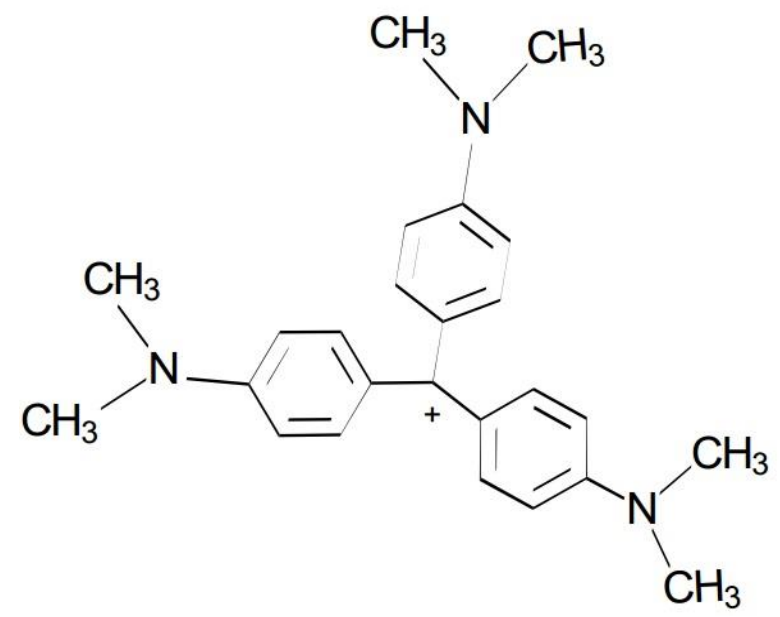

Fig. 5. Structure of crystal violet (CV).

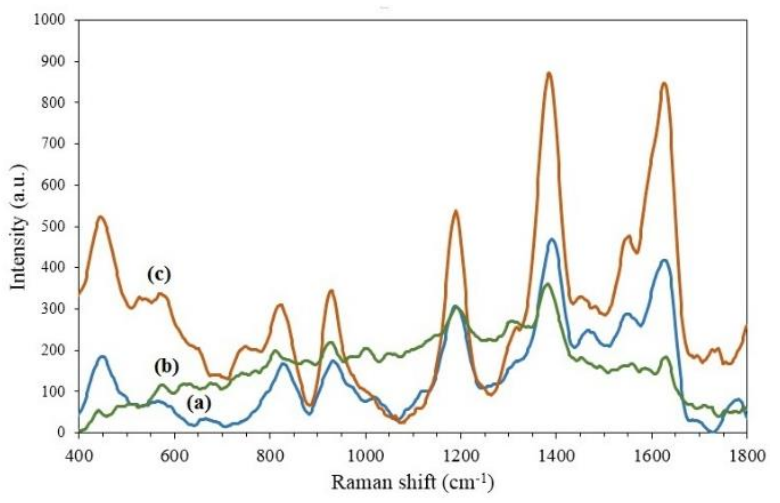

Fig. 6. Raman spectra of crystal violet (CV), (a): powder sample, and solutions with different concentrations including (b): $0.1 \mathrm{mM}$, and (c): $1 \mathrm{M}$.

After using the self-assembled substrates, SERS spectra are collected. Ag NPs with different particle sizes (samples-1, 2) and $\mathrm{Au} @ \mathrm{Ag}$ NPs (sample-3) were used as substrates to acquire SERS spectra of CV analyte with $0.1 \mathrm{mM}$ concentration. The SERS spectra are shown in Fig. 7.

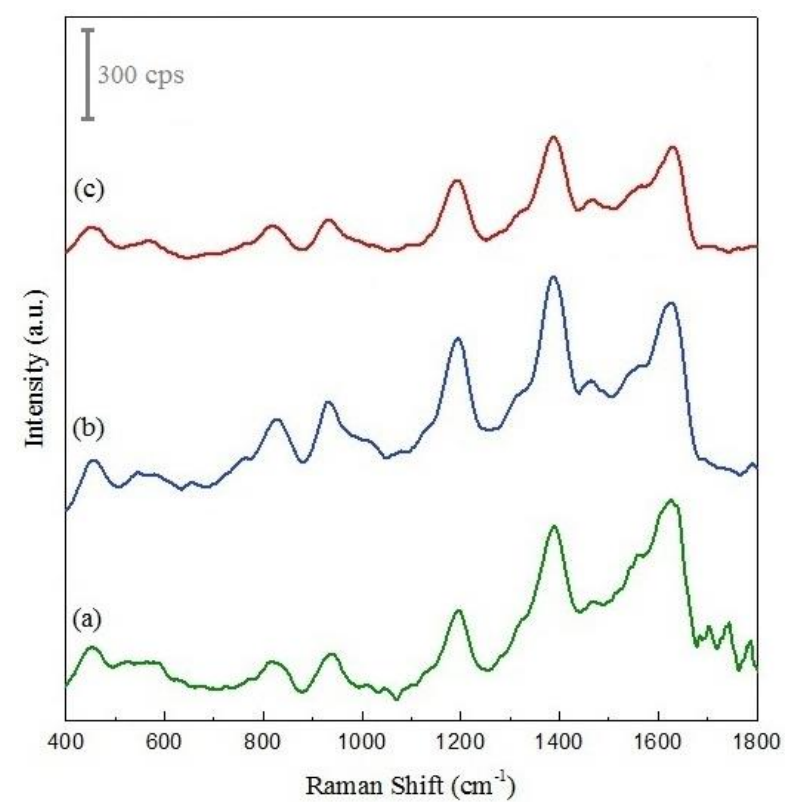

Fig. 7. SERS spectra of $0.1 \mathrm{mM}$ aqueous solution of crystal violet (CV) adsorbed on (a): sample-1, (b): sample-2, and (c): sample-3.

The assignment peaks of SERS spectra are summarized in Table 1. These vibrational modes fall within the related wavenumbers reported in the literature [22]. The enhancement of Raman spectra of CV on the substrates can be demonstrated by calculating the related enhancement factors (EFs). The SERS EFs were calculated based on the most widely used equation:

$\mathrm{EF}=\frac{I_{S E R S} / C_{S E R S}}{I_{R S} / C_{R S}}$

In the aforementioned equation $I_{R S}$ corresponds to the Raman intensity obtained under non-SERS conditions at an analyte concentration of $C_{R S}$, and $I_{\text {SERS }}$ corresponds to the Raman intensity obtained for the SERS substrate under a certain concentration of $C_{\text {SERS }}$. The experimental conditions, such as the laser wavelength, laser power, microscope objective or lenses, spectrometer, and measuring conditions on the substrate, are identical in all cases.

Based on the characteristic peak at $1626 \mathrm{~cm}^{-1}$ and using $\mathrm{C}_{\mathrm{RS}}=1 \mathrm{M}, \mathrm{C}_{\mathrm{SERS}}=10^{-4} \mathrm{M}$ and the intensities obtained from Fig. 7, the EFs of substrates were estimated to be about $9.5 \times 10^{3}$, 
$9.2 \times 10^{3}$, and $4.8 \times 10^{3}$ corresponding to the sample-1, sample-2, and sample-3, respectively.

Table 1. Peak assignments of crystal violet (CV) measured in SERS spectra, $(v$ : stretching vibration ( $\mathrm{s}$ : symmetric; as: antisymmetric; $\delta$ : bending vibration; $\rho$ : rocking; $\gamma$ : out-of-plane deformation)

\begin{tabular}{|c|c|c|c|}
\hline \multirow{2}{*}{ Assignment } & \multicolumn{3}{|c|}{$v_{S E R S}\left(\mathrm{~cm}^{-1}\right)$} \\
\hline & Sample-1 & Sample-2 & Sample-3 \\
\hline$v_{s}(C-C)$ & 1626 & 1628 & 1630 \\
\hline $\boldsymbol{\delta}_{\mathrm{as}}\left(\mathrm{CH}_{3}\right)$ & 1468 & 1464 & 1468 \\
\hline $\begin{array}{l}\delta(\mathrm{CH}) / \delta_{\mathbf{s}}\left(\mathrm{CH}_{3}\right) / \\
\delta(\mathrm{CCC})_{\text {ring }} \\
\end{array}$ & 1389 & 1387 & 1387 \\
\hline $\mathbf{v}_{\text {as }}\left(\mathrm{CC}_{\text {center }} \mathrm{C}\right)$ & 1196 & 1194 & 1192 \\
\hline $\boldsymbol{\rho}\left(\mathrm{CH}_{3}\right) / \mathbf{v}(\mathbf{C N})$ & 935 & 932 & 934 \\
\hline $\boldsymbol{\delta}\left(\mathbf{C C}_{\text {center }} \mathbf{C}\right)$ & 814 & 827 & 820 \\
\hline $\begin{array}{l}\gamma(\mathbf{C C C}) / \boldsymbol{\delta}(\mathrm{CNC}) / \\
\delta\left(\mathrm{CC}_{\text {center }} \mathbf{C}\right)\end{array}$ & 563 & 579 & 567 \\
\hline$\delta(\mathbf{C N C})$ & 453 & 453 & 449 \\
\hline
\end{tabular}

Enhancement factors indicated that all three substrates were well able to reveal very low concentrations. Because of the similarity of the absorption spectra of larger Ag NPs and the gold-silver core-shell NPs, it was expected that sample-2 and sample-3 behave in the same way as Raman signal enhancement, but the calculated EF values differed significantly, and $\mathrm{Ag}$ NPs performed better in Raman signal enhancement. This is due to the electromagnetic fields decay exponentially in metals, and that core-shell NPs only consist of a thin outer shell of silver on gold NPs, and thus do not have the same optical properties of pure Ag NPs with the same size.

The optical absorption of silver is the reason for the high signal enhancement by the silver substrates, because interband transitions play a key role in the intensity of SERS. The interband transition of silver metal occurs in the UV region, therefore its absorption at the visible Raman laser wavelength, $532 \mathrm{~nm}$, results in high Raman signal intensities [23].

The results of sample- 1 and sample- 2 are not in full agreement with theoretical predictions and experimental data, because it was expected that as the size of Ag NPs increases, the electromagnetic field enhances and the stronger surface plasmons provides higher enhancement. But it should be also considered with self-assembly on the surface of the glass, nanoparticles tend to aggregate and as a result, their size will increase. Thus, the small nanoparticles approach to the optimal size to achieve high Raman signal intensities [24]; In contrast, the ability of larger nanoparticles (sample-2) in detecting will decrease.

\section{Conclusion}

Self-assembly of nanoparticles on glass is an efficient, low-cost, and easy method to prepare SERS substrates. To this end, substrates of gold-silver core-shell nanoparticles with an approximate diameter of $39 \mathrm{~nm}$ with Ag NPs in two different sizes ( 8 and $35 \mathrm{~nm}$ ) were synthesized. Their function in detecting Raman modes using CV pigment was investigated and compared. The results showed that in the same experimental conditions, such as frequency and laser power, the strongest signal was recorded by the smallest Ag NPs substrate. All three substrates well detected Raman modes of $0.1 \mathrm{mM}$ of CV solution, and the highest EF $\left(9.5 \times 10^{3}\right)$ is related to the Ag NPs with the smallest size.

\section{REFERENCES}

[1] M. Moskovits, "Surface-enhanced spectroscopy," Rev. Mod. Phys, Vol. 57, pp. 783-826, 1985.

[2] A. Otto, "The chemical (electronic) contribution to surface-enhanced Raman scattering," J. Raman Spectrosc, Vol. 36, pp. 497-509, 2005.

[3] A. Campion and P. Kambhampati, "Surfaceenhanced Raman scattering," Chem. Soc. Rev, Vol. 27, pp. 241-250, 1998.

[4] L. M. Liz-Marzan, "Tailoring Surface Plasmons through the Morphology and Assembly of Metal Nanoparticles," Langmuir, Vol. 22, pp. 32-41, 2006.

[5] R. Jiang, H. Chen, L. Shao, Q. Li, and J. Wang, "Unraveling the Evolution and Nature of the Plasmons in (Au Core)-(Ag Shell) Nanorods," Adv. Mater, Vol. 24, pp. 200-207, 2012. 
[6] M.F. Cardinal, B. Rodriguez-Gonzalez, R.A. Alvarez-Puebla, J. Perez-Juste, and L.M. LizMarzan, "Modulation of Localized Surface Plasmons and SERS Response in Gold Dumbbells through Silver Coating," J. Phys. Chem. C, Vol. 114, pp. 10417-10423, 2010.

[7] A.K. Samal, L. Polavarapu, S. Rodal-Cedeira, L.M. Liz-Marzan, J. Perez-Juste, and I. Pastoriza-Santos, "Size tunable Au@Ag coreshell Nanoparticles: Synthesis and SurfaceEnhanced Raman Scattering Properties," Langmuir, Vol. 29, pp. 15076-15082, 2013.

[8] A. Sanchez-Iglesias, E. Carbo-Argibay, A. Glaria, B. Rodriguez-Gonzalez, J. Perez-Juste, I. Pastoriza-Santos, and L.M. Liz-Marzan, "Rapid Epitaxial Growth of $\mathrm{Ag}$ on $\mathrm{Au}$ Nanoparticles: From Au Nanorods to CoreShell Au@Ag Octahedrons," Chem.-Eur.J, Vol. 16, pp. 5558-5563, 2010.

[9] M.S. Shore, J. Wang, A.C. Johnston-Peck, A.L. Oldenburg, and J.B. Tracy, "Synthesis of $\mathrm{Au}($ Core $) / \mathrm{Ag}$ (Shell) Nanoparticles and their Conversion to AuAg Alloy Nanoparticles," Small, Vol. 7, pp. 230-234, 2011.

[10] M. Fan and A. G. Brolo, "Silver nanoparticles self-assembly as SERS substrates with near single molecule detection limit," Phys. Chem. Chem. Phys. Vol. 11, pp. 7381-7389, 2009.

[11]L. Zhang, "Self-assembly Ag nanoparticle monolayer film as SERS Substrate for pesticide detection," Appl. Surf. Sci. Vol. 270, pp. 292-294, 2013.

[12]L. Mulfinger, S.D. Solomon, M. Bahadory, A. V. Jeyarajasingam, S.A. Rutkowsky, and C. Boritz, "Synthesis and study of silver nanoparticles," Appl. Surf. Sci, Vol. 84, pp. 322-325, 2007.

[13] S. L. Smitha, K.M. Nissamudeen, D. Philip, and K. G. Gopchandran, "Studies on Surface Plasmon Resonance and Photoluminescence of Silver Nanoparticles," Spectrochim. Acta A, Vol. 71, pp. 186-190, 2008.

[14]G. Frens, "Controlled Nucleation for the Regulation of the Particle Size in Monodisperse Gold Suspensions," Nat. Phys. Sci. Vol. 241, pp. 20-22, 1973.

[15] D.M. Mott, D.T.N. Anh, P. Singh, C. Shankar, and S. Maenosono, "Electronic Transfer as A Route to Increase The Chemical Stability In Gold And Silver Core-Shell Nanoparticles,"
Adv. Colloid Interface Sci. Vol. 185-186, pp. 14-33, 2012.

[16] S. Zhu, C. Fan, J. Wang, J. He, and E. Liang, "Self-Assembled Ag Nanoparticles for Surface Enhanced Raman Scattering," Opt. Rev. Vol. 20, pp. 361-366, 2013.

[17] K. Mallik, M. Mandal, N. Pradhan, and T. Pal, "Seed Mediated Formation of Bimetallic Nanoparticles by UV Irradiation: A Photochemical Approach for the Preparation of Core-Shell Type Structures," Nano Lett. Vol. 1, pp. 319-322, 2001.

[18] G.S. Bumbrah and R.M. Sharma, "Raman spectroscopy-Basic principle, instrumentation and selected applications for the characterization of drugs of abuse," Egypt. J. Forensic Sci. Vol. 6, pp. 209-215, 2016.

[19]T. Sato, D. Brown and B.F.G. Johnson, "Nucleation and growth of nano-gold colloidal lattices," Chem. Commun. Vol. 11, pp. 10071088, 1997.

[20]E.J. Liang, X.L. Ye, and W. Kiefer, "SurfaceEnhanced Raman Spectroscopy of Crystal Violet in the Presence of Halide and Halate Ions with Near-Infrared Wavelength Excitation," J. Phys. Chem. A, Vol.101, pp. 7330-7335, 1997.

[21]H.P.J.M. Dekkers and E.C.M. Kielman-Van Luyt, "Magnetic circular dichroism of the triphenylcarbenium ion and some symmetrically para-substituted derivatives," Mol. Phys. Vol. 31, pp. 1001-1019, 1976.

[22] C. De Rosa, F. Auriemma, C. Diletto, R. Di Girolamo, A. Malafronte, P. Morvillo, G. Zito, G. Rusciano, G. Pesce, and A. Sasso, "Toward Hyperuniform Disordered Plasmonic Nanostructures for Reproducible SurfaceEnhanced Raman Spectroscopy," Phys. Chem. Chem. Phys. Vol. 17, pp. 8061-8069, 2015.

[23]P.R. West, S. Ishii, G.V. Naik, N.K. Emani, V.M. Shalaev, and A. Boltasseva, "Searching for better plasmonic materials," Laser Photon. Rev. Vol. 4, pp. 795-808, 2010.

[24] K.G. Stamplecoskie and J.C. Scaiano, "Optimal Size of Silver Nanoparticles for Surface-Enhanced Raman Spectroscopy," J. Phys. Chem. C, Vol. 115, pp. 1403-1409, 2011. 


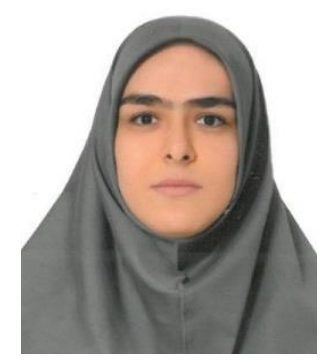

Bahareh Morovvati was born in Tehran, I.R. Iran, in 1990. She received her BSc degree in Physics from Amirkabir University of Technology (AUT), I.R. Iran in 2013 and her MSc degree from Tarbiat Modares University, Tehran, I.R. Iran in 2016. The title of her MSc dissertation is: "A feasibility of substrate fabrication from multi-walled carbon nanotubes (MWCNTs) and metallic nanoparticles in identification of $\mathrm{CV}$ and $\mathrm{RB}$ solutions with low concentrations by surface enhanced Raman spectroscopy (SERS).”

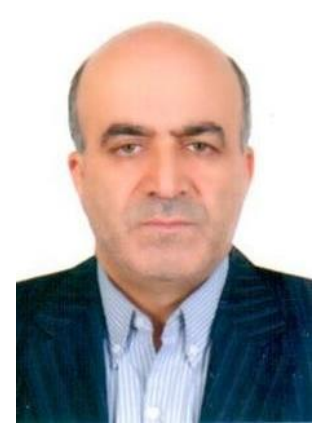

Rasoul Malekfar received his BSc in Physics in 1980 from Pars College, Tehran, I.R. Iran, MSc in theoretical Physics in 1984 from University of Kent at Canterbury, U.K. and $\mathrm{PhD}$ in experimental Physics, laser Raman spectroscopy, from King's College, University of London in 1989. He is currently engaged as a Professor of Physics in Atomic and Molecular Physics Group, Physics Department, Tarbiat Modares University, Tehran, I.R. Iran. 